\title{
PICO DELLA MIRANDOLA Y SAVONAROLA
}

\author{
Pico della Mirandola \& Savonarola
}

\section{Jorge Velázquez Delgado}

UAM, México

"Nuestro afán no consiste en estar

libre del pecado, sino en ser Dios"

\section{Plotino}

\section{Resumen}

En este artículo se aborda la relación entre Gerolamo Savonarola y Giovanni Pico de la Mirandola, partiendo de la base de la amistad que sostuvieron ambos y problematizando la dificultad que se presenta ante dos personalidades aparentemente irreductibles. En tanto que símbolos emblemáticos del Renacimiento italiano, su análisis supone un análisis de las ideas y el ethos del período.

Palabras clave: Renacimiento, ethos, semblantes.

\begin{abstract}
This article addresses the relationship between Giovanni Girolamo Savonarola and Pico della Mirandola, on the basis of the friendship that they held and questioning the difficulty to face with two apparently irreconcilable personalities. As emblematic symbols of the Italian Renaissance, the analysis of both is an analysis of the ideas and ethos of the period.
\end{abstract}

Keywords: Renaissance, Ethos, Countenances.

\section{Introducción y a modo de justificación}

Toda reconstrucción filosófica ${ }^{1}$ exige e implica una infinidad de cuestiones las cuales no siempre resultan ser ampliamente satisfactorias para quien se atreve a incursionar o problematizar --desde su propio horizonte crítico-ideológico-- alguno de los intricados paisajes de la historia de la filosofía. Menos aún es abreviar al extremo y para los fines exclusivos de una

\footnotetext{
${ }^{1}$ Entendemos por reconstrucción filosófica el análisis de una problemática filosófica la cual es referida a un paradigma, temática concreta, concepto o a la vida de un filósofo. Lo que importa en dicha reconstrucción es abordarla tomando como campo de referencia para el análisis métodos, conceptos y categorías filosóficas o, en su defecto, contextos históricos en el que los textos comentados o analizados impliquen ser fundamentados filosóficamente.
} 
presentación sencilla como es la que nos tiene acostumbrados la tiranía de la academia en este tipo de reuniones, exponer frente a un público tal vez poco interesado o quizá morbosamente curioso pero eso sí muy exigente, lo que se dirá sobre algún filósofo vivo o pretérito que deambula por alguna extraña razón entre nosotros. La historia de la filosofía es un campo muy fértil pero poco labrado. Para algunos es un referente de poco interés y que, por lo mismo, se presta al engaño o al apilamiento de notas y datos que para lo que sirven es para dar avisos oscuros e inconsistentes a quienes se atreven a tener entre sus manos alguna historia de la filosofía. No es casual que esos libros se vean como anecdotarios que hablan de los filósofos en términos generalmente corteses pero poco interesante o atractivos para lo que se considera debe ser el trabajo duro y preciso o sistemático de todo estudioso de la filosofía. A la biografía se acepta en general con muchas reticencias y en no pocas ocasiones se le adopta como un género lejanamente subsidiario de la filosofía. Lo que se pide de este modo a todo aquel que inicia sus incursiones por los laberintos de la filosofía, es que llegue a adquirir mentalidad de filósofo y no de historiador. Pero por suerte continua siendo la historia de la filosofía la columna vertebral de nuestra formación filosófica: un indispensable referente que señala que el filósofo es de algún modo si no un historiador si un profesional de la filosofía que debe tener tanto una mentalidad de historiador como una amplia y abierta conciencia histórica.

Son estas consideraciones fundamentales y generales las que influyen determinantemente en nuestra forma de percibir lo que ha sido hasta la fecha la historia de la filosofía: una narración o relato histórico con presupuestos de índole historiográfico y con ribetes de historicismo en lo que todo lo ocurrido en este particular campo de la experiencia humana, se ve de forma lineal y evolutiva en el cual la única referencia para diferenciar sus líneas divisorias es encuadrar a los filósofos ya sea por sólidos bloques temporales y por corrientes. $\mathrm{Al}$ menos hoy las historias de la filosofía no son tan maniqueas como lo fueron hasta hace poco tiempo en que sólo se pensaba en términos de idealismo y materialismo. Cosa que no quiere decir que las cosas sean diferentes en referencia a que el historiador no es ajeno a los juegos ideológicos que reproduce a veces de forma muy sofisticada la misma filosofía. Lo que de toda esta experiencia se pude decir es que no existe a la fecha ningún criterio 
historiográfico que satisfaga las expectativas de lo que se antoja debe ser la historia de la filosofía. Lo que se tiene son historia generales que sirven más como manuales o introducciones a la filosofía o verdaderos trabajos formados por varios tomos que al final resultan ser simples textos de consulta o cómodas referencias al pie de página. En un caso más sugerente, la historia de la filosofía es también la experiencia que de sí tiene la propia filosofía como campo de reflexión autónomo en el cual los acontecimientos dejan de ser simples hechos históricos para convertirse en verdaderos conceptos filosóficos. El historicismo es --dicho muy gruesamente-- ese campo de la reflexión filosófica mediante el cual se pretende dar razón de la historia. No es, rigurosamente hablando, historia de la filosofía. Es un modo filosófico para hablar de lo que el hombre es y ha sido en su drama histórico.

Lo que enseña la historia de la filosofía es que nunca los procesos históricos son homogéneos ni que deban ser tomados como tales. Que cada época o periodo histórico está atiborrado de filósofos de diversas estaturas. Las historias de la filosofía son esos extraños libros de interés particular que se consultan eventualmente para saber sucintamente qué dijo aquel filósofo de nuestro interés o en qué consiste tal corriente filosófica. Son, como se ha dicho, textos de consulta a los que en general no se les otorga alguna considerable autoridad. Lo que ahí predomina son los grandes filósofos o las grandes corrientes filosóficas de lo que hasta hoy es la filosofía occidental. Lo que en ellos se ve son cumbres y nunca todo el paisaje. Es una historia de la filosofía elaborada con los rígidos criterios de la modernidad. Es con base a dichos criterios que las expresiones filosóficas que no se ajustan a lo que se considera que es la experiencia de la modernidad, simplemente o son escatimadas o no existen. En caso de existir alguna relevancia mínimamente significativa ésta se hace siempre y cuando todo termine por ser ajustado a una condición premoderna, protomoderna o al hecho de demostrar cómo esa experiencia tendía inevitablemente a ser parte del proceso global de configuración de la modernidad. Que históricamente todo ha conducido a la construcción de la modernidad tal y cual la conocemos y tal y como es narrada en esos grandes relatos históricos. La imagen de la historia de la filosofía es la de un proceso histórico de carácter evolutivo --cinmanente?-- en el que todo el pasado se piensa como un proceso necesario a la configuración de la modernidad. 


\section{El problema del Renacimiento}

Hasta hoy la serie de estudios que hemos venido realizando sobre el Renacimiento italiano y sobre la cultural del Barroco tratan de romper con un ambiente cultural y académico en el cual a pesar de la cada vez más densa crítica que existe sobre los valores y criterios que se piensan son propios y correspondientes para hablar de la normalidad de la modernidad, éstos no dejan de imponerse y reproducirse generando una hegemonía en la que todo lo que no sea de interés para una academia y para una cultura cimentada bajo dichos referentes, es llevado a las catacumbas de la marginalidad. Los estudios e investigaciones sobre estos dos vitales procesos históricos están logrando --a duras penas-- tener un reconocimiento obtenido más por el empeño terco de sus interesados que por la nobleza de todos los tópicos a los que se refiere dicha experiencia. Al parecer se tiene un avance considerable pero insuficiente en nuestro país y en Latinoamérica sobre la condición actual de tales estudios. Y lo difícil aquí es cómo romper el círculo vicioso que reproduce esa hegemonía a partir de la condición periférica y marginal bajo la cual se realizan investigaciones en torno a las más representativas figuras de la filosofía del Renacimiento y del barroco.

No es el caso de exponer aquí todo lo que implica sostener proyectos de investigación decorosos bajo las condiciones actuales en las que no es posible hablar de la existencia de una tradición equiparable a otras propuestas en nuestro medio académico-cultural. El reto es forjar las condiciones mínimas para la existencia y sobre vivencia de una tradición que alcance un significativo reconocimiento al interior de nuestros respectivos centros como fuera de ellos.

Ahora bien, el problema del Renacimiento se refiere a la relación y papel que ha desempañado este vital proceso histórico al interior del proceso global de construcción de la modernidad. El debate historiográfico que se ha desarrollado en torno a tal problema, se produce y se reproduce como una cuestión ajena o de poco interés para la filosofía. Históricamente hablando se culpa a la propia filosofía porque no ha contribuido a esclarecer cuáles fueron las verdaderas aportaciones que dieron los filósofos renacentista a la modernidad. No es casual por ello que a este periodo histórico se le asuma como un tiempo en el que no 
existen verdaderas aportaciones filosóficas. Lo que se percibe a simple vista son destellos, ideas confusas, mentes de gran ingenio, secretismos inauditos, en suma: simples balbuceos filosóficos que jamás aterrizan en nada. Lo que ofrece el Renacimiento es la imagen narcisista de sí mismo en la que lo que invariablemente termina por admirarse es a su la inconfundible masa de hombres egregios. A un periodo de la historia occidental en la que predominan y adquieren mayor relevancia los artistas. Se asienta por ello como lo propio y definitivo del Renacimiento ser la edad de los grandes artistas. Lo que se admira de éste es al enjambre de individualidades de gran talento e ingenio. Hombres que con sus respectivos matices y macizas personalidades se les atribuye ser responsables de encauzar los primeros momentos de la modernidad. Son estas grandes individualidades que van del artesano al más inmortal artista pasando por el banquero, el profeta, el dictador, el codottiero e incluso el filósofo, quienes contribuyeron a producir tal ethos socio-cultural que a la par de continuar generando una gran admiración no deja de lanzar interrogantes en infinidad de sentidos.

\section{El ethos socio-cultural del Renacimiento}

Al otorgársele un lugar poco definido en los combates por la modernidad y al ser considerado un tiempo en el que no se ven claros referentes filosóficos, al Renacimiento se le piensa más como parte de las tinieblas medievales que como la aurora de la modernidad. Es la fuerza inconfundible de su sincretismo lo que mejor habla de lo que fue el Renacimiento. Como es también, por otro lado, su reconocido Humanismo un referente que permite comprender que en ese ethos socio-cultural lo que se debatía era algo más profundo y complejo que la simple inquietud por conservar una cultura y una mentalidad las cuales, por cierto, para esos hombres eran de una importancia y significado muy diferente al que en general se les atribuye. Por decirlo en estos términos: el Renacimiento no es una reacción medievalizante como quizá lo fue la Reforma protestante con todo y su Calvino a la cabeza. Fue un tiempo en el que el dinero y la forma de obtenerlo y de gastarlo o derrocharlo, marcó los destinos de una sociedad. Es a partir de este momento cuando la relación entre el dinero y el poder será lo esencialmente determinante del mundo moderno. Y que las cosas las queramos 
ver después como algo claro y distinto, eso será otro asunto. En todo caso que las cosa las ajustemos a pesos y medidas es producto y consecuencia de esta digamos prosaica práctica que introduce al mundo esos hombres de la sociedad renacentista a partir de soldar fatalmente la relación entre el poder y el dinero. Es esta relación la que más ha contribuido a arrojarnos al mundo -a mundanizarnos, pues-- como es también la que nos quita el peso de quien sabe que tantas culpas.

Desde entonces a la fecha el mundo civil no se rige por lo bueno o por lo malo, sino por lo correcto e incorrecto de nuestros actos y por la eficacia de los mismos. Decir con Nietzsche que el Renacimiento es esa época alegre del mundo es tanto como entender que lo que ahí se reproducía eran las coordenadas de un ambiente social en el que la culpa no es algo fatal. Menos aún cuando lo único que sabemos del mundo es únicamente lo que en él existe: Una infinita serialidad de entes finitos. Una relación en la cual una vez que se toma conciencia de la propia finitud humana, se buscan nuevos caminos de inmortalidad. Otros senderos de gloria que en nada se asemejan a los viejos planteamientos teológico-religiosos. Por ser ahora éstos radicalmente mundanos. Expresión a la vez de un mundo civil en el que el Humanismo republicano lleva a colocar a las cosas de la religión en su justa dimensión terrena. Pero lo que a fin de cuentas no se acepta de esta ambiente sociocultural es a su inconfundible sincretismo. Por decir las cosas en pocas líneas: a partir de la modernidad hemos aprendido a admirar la grandeza del Renacimiento y a valorarla como una de las más importantes experiencias humanas. Lo que no hemos aprendido es a valorar cabalmente su sincretismo. Es decir, a todo ese cúmulo de experiencias e influencias pretéritas que encuentran amplia recepción en un ethos tan abierto como lo fue esa sociedad en la que al parecer todo era posible menos toda milagreria barata.

Con la cultura del Renacimiento no se descubren únicamente los mitos y restos vivientes de la antigüedad greco latina. Pues se aprecian y valoran con gran intensidad los mitos y restos de otras culturas que dejaron también su huella en ese pequeño gran sistema-mundo que fue el Mediterráneo. Es esto lo insólito del Renacimiento: que haya fijado la mirada más allá del hombre grecolatino. Hecho que no obligadamente se traduce en ser el Renacimiento el esfuerzo de orientalización de la filosofía occidental. En tal sentido la clave 
hermenéutica no está en el sincretismo renacentista. La clave hermenéutica la tenemos en la capacidad que mostró el arte en general y la filosofía en particular para sintetizar referentes históricos de diferente facturación socio-cultural. Es esta clave lo que nos permite entender las coordenadas de una nueva metafísica de la unidad así como la búsqueda de una armonía filosófica como basamento de la tan deseada paz perpetua entre los hombres. Como es a la vez lo que nos permite hablar de lo que en verdad es el problema central de la filosofía del Renacimiento. La filosofía del Renacimiento la definimos como la primera filosofía de la modernidad que parte del problema de forjar la metafísica del hombre ontocreador.

\section{Los semblantes}

Dado un ethos socio-cultural tan heterogéneo como lo es en particular el de la sociedad del Renacimiento italiano, resulta difícil hablar de sus grandes personalidades sin considerar algunos problemas entre los que se tienen a los de orden metodológico. Es ya una costumbre muy arraigada por ejemplo que cuando se hace referencia a algún artista o a un filósofo se haga aislándolo de su contexto. El Renacimiento se ve por esto como si fuese producto de un amplio mosaico en el que cada cuadro es autónomo, un compartimiento estanco o una verdadera monada que --como las de Leibniz-- no tienen ventanas. Pero no hay nada más falso que esto. Ninguna temporalidad se comporta de esta manera. Su reproducción sería imposible. Como lo sería también su comprensión. Lo que demuestran los más serios estudios sobre el Renacimiento es que al igual que toda época histórica de gran trascendencia, ésta fue también producto de un intenso debate que refleja la dimensión que adquirían las ideas tanto en su producción como en su circulación e intercambio. Es esto lo que coloca a esos hombres - como las Sibilas y Profetas de Miguel Angel- en la misma altura. Sus diferencias pasan a depender de la importancia y sentido de su actividad en dicho ethos socio-cultural. Como del modo de recepción que con el paso del tiempo se hace de ellos. Es decir, por la valorización histórica o crítica que se hace de sus obras o por su metamorfosis en mito viviente en un determinado contexto histórico. Particular consideración es la que se debe hacer, por ejemplo, del hombre cósmico u hombre vitruviano en varios sentidos: en 
primer lugar en sus referentes míticos de la antigüedad y, en segundo lugar, en la discusión renacentista sobre el lugar que ocupa el hombre en el universo. Esto es: en referencia al problema de la libertad del hombre en su comprensión absolutamente moderna y, por lo mismo, secular. A lo que se refiere dicha discusión es al problema antropológico y ontológico de la nueva concepción del hombre que propone la filosofía renacentista.

Contrastar a las enormes personalidades del Renacimiento permite al menos establecer escalas de diferenciación para hablar de individuos tan opuestos como lo es por ejemplo el mecenas y el artista; el condottiero y el filósofo o entre el comerciante y la cortesana. En el caso de la relación entre Gerolamo Savonarola y Giovanni Pico de la Mirandola al parecer es poco lo que de ellos se puede hablar más allá de la incuestionable y leal amistad que mantuvieron ${ }^{1}$. Todo apunta a sospechar que entre el filósofo y el profeta existe un abismo infranqueable. Que son personalidades irreductibles. Y que es imposible incluso aplicar a ellos una metodología como la que establece el historiador y biógrafo Plutarco ${ }^{2}$. Pues a primera vista se nos aparecen como

\footnotetext{
${ }^{1}$ La amistad entre ellos nunca fue un hecho anecdótico. Por decirlo en estos términos: fue vital y profunda. Pero sobre el tema ver en especial: Rocca, Paolo. Giovanni Pico della Mirandola nei sui rapporti di amicizia con Gerolamo Savonarola. Ferrara. Università degli Studi di Ferrara. 1964.

2 A nuestro criterio hasta la fecha la biografía más autorizada sobre Gerolamo Savonarola continúa siendo la de Pascuale Villari. La storia di Girolamo Savonarola e de sui tempi. Florencia. Felice le Monnier. 1930. Dos vols. Por su relación e importancia tenemos a la biografía que sobre el frate realizó Gianfrancesco Pico della Mirandola. Vita Hieronymi Savonarolae. Florencia. Leo S. OLschki. 1999. Otros importantes estudios biográficos sobre la vida del sacerdote dominicano son: Gualazzi, Enzo. Savonarola. Milán. Rusconi. 1982. Antonetti, Pierre. Savonarola "il profeta disarmato". Milán. Biblioteca Universale Rizzoli. 1998. Scaltrini, Giacinto. Masciattelli, Piero. Savonarola. Milán. Alpes. 1979. Cagna, Nuccia. Gerolamo Savonarola. Turín. Società Editrice Internazionale. 1949. Ceccuti, Cosimo. Savonarola. Tra medioevo e Rinascimento. Florencia. Octavo. 1998. Entre lo que consideramos como parte de los estudios críticos sobre la acción y pensamiento de Savonarola está el magnifico e insuperable estudio de Franco Cordero editado en cuatro volúmenes por la editorial Laterza. I. Savonarola. Voce calamitosa. 1452-1494. II. Savonarola. Il profeta delle maraville. 1494-1495. III. Savonarola. Demiurgo sanza politica. 1496-1497. IV. Savonarola. Agonista perdente. 1497-1498. En referencia a sus ideas políticas ver en especial del propio Gerolamo Savonarola: Trattato sul governo di Firenze. Roma. Riuniti. 1999. existe una versión en español cuya estudio introductorio lo realiza Francisco Fernández Buey. Tratado sobre la República de Florencia y otros escritos políticos. Veáse también el clásico estudio de Weinstein, Donald. Savonarola e Firenze. Profezia e patriotismo nel Rinascimento. Bolonia. Il Mulino. 1976. Guccione, Eugenio. Girolamo Savonarola nel pensiero politico-sociale dei cattolli italiani ttra il XIX e XX secolo. Palermo. Presso L’Accademia. 1978. Ver también: Varios. Studi savonaroliani. Atti e Memorie. Ferrara. Diputazione Privinciale Ferrarese di Storia Patria. 1952-3. Tres vols. Sobre el juicio a Savonarola ver en especial: Scaltriti, Giacinto. L'ultimo savonarola. Esamene giuridico-teologico del cartegio (breve lettere) intercorsi tra Papa Alessandro VI e il Frate Girolamo Savonarola. En español se han publicado: Ríos Mazcarelle. Savonarola. Una tragedia del Renacimiento. España. Merino. 2000. De Lejendio Luis María. Savonarola
} 
entidades diametralmente opuestas en diversos sentidos. Sin embargo, no por ello podemos dejar de reconocer que Mirandola y Savonarola serán indefinidamente dos de las más grandes figuras emblemáticas de todo lo que fue y representa a la fecha el Renacimiento italiano.

De acuerdo con lo que José Ortega y Gasset considera que es la temporalidad tajante de una generación, no se aplica a ellos pues il frate responde a una generación diferente; la que va con la segunda mitad del siglo XV. Gerolamo Savonarola nace en 1452. La del Conde responde a la siguiente generación en cuanto que nace en 1463. De acuerdo con el criterio orteguiano para medir la fuerza generacional, estas resultan ser incompatibles. Más aún cuando el segundo muere en 1494 y el primero en 1498. Lo que terminan por compartir es un mismo lugar de nacimiento: la ciudad de Ferrara. Y el mismo lugar de su muerte: la ciudad de Florencia. Socialmente es también muy poco lo que comparten. Mirandola es un noble; Savonarola es miembro de una familia adinerada. Filosóficamente no tienen puntos de contacto pues mientras uno es reconocido incluso como Príncipe de los filósofos, el otro es un religioso entregado a su vocación. Físicamente es ridículo hacer una comparación pues todos hablan de la belleza de Giovanni Pico Della Mirandola prefiriendo no hacer mención de la fealdad del sacerdote dominicano. Uno de los más importantes y reconocidos biógrafos de las grandes individualidades del Renacimiento, Marcel Brion, de un disparo que va directo a la cabeza del lector, detalla de la siguiente manera la personalidad de Savonarola:

"Era feo. Con fealdad agresiva y dolorosa. Jamás se dirá cuánto entra de rencor personal en el furor de los iconoclastas. Sería absurdo hacer depender de aquella fealdad el sentido de su apostolado; pero no se pueden ignorar cuán abrumadoramente ha pesado sobre su juventud, de qué modo los impulsos naturales de su corazón hacia el amor, hacia la alegría, hacia la expansión física, han sido contrariados por su rostro desgraciado,

(Estudio biográfico). Madrid. Espasa-Calpe. 1960. Huerga, Álvaro. Savonarola. Reformador y profeta. Madrid. Biblioteca de Autores Cristianos. 1978.

Con respecto a los estudios biográficos y críticos sobre de la obra y pensamiento de Giovanni Pico della Mirandola se pueden citar: Fumagalli Beonio Brocchieri, Mariateresa. Pico della Mirandola. Florencia. PIEMME. 1999. Graven, William. Pico della Mirandola. Un caso Storiografico. Bolonia. Il Mulino. 1985. Lubac, Henri de. L'alba incompleta del Rinascimento. Pico della Mirandola. Milán Jaka Book. 1977. Varios. L'opera e il pensiero di Giovanni Pico della Mirandola nella storia dell'umanesimo. Convegno Internazionale. Florencia. Istituto Nazionale di Studo sul Rinascimento. 1965. 
por aquella enorme nariz, prominente y corva, aquella boca violenta con el labio inferior colgante; y la expresión de padecimiento que hay en todos sus retratos no revela únicamente el dolor de un alma que anhela lo puro y lo absoluto, sino también la tristeza por una imperfección física que desde su juventud lo ha apartado de todos"1

Hasta aquí es evidente que el filósofo y el profeta no comparten nada. Que la única forma de establecer relaciones entre ellos es mediante un referente común: el ethos renacentista. Pero incluso con esto no son vidas paralelas. Son vidas entrecruzadas que al parecer dependen más del conatus que de haber compartido un proyecto de vida, político, ideológico o cultural en común. En otro plano del asunto, y esto es ya lo más importante, compartieron una misma pasión mística la cual al ser llevada por uno a las antinomias filosóficas y por otro a sus desplantes proféticos, cargaron de indescriptible fuerza al de por sí denso ambiente florentino. Desde nuestro punto de vista la relación no se detiene aquí; falta un ingrediente vital que más allá de imaginar al Conde vestido con hábito dominicano diciendo con ello que quiere ser parte de la orden del frate. El elemento que falta tiene mucho que ver con la famosa disputa astrológica del Renacimiento. Cosa que nos lleva a no perder de vista lo que ellos sabían que se gestó en su natal Ferrara, pero sobre todo en la generalizada mentalidad prototípica del hombre del Renacimiento.

\section{El horizonte hipotético de los orígenes del Renacimiento y la disputa astrológica}

Desde tiempos antiguos ha existido una apasionada discusión en torno al papel que juegan los astros en los destinos humanos ${ }^{2}$. En el Renacimiento italiano esta discusión abre definitivamente la posibilidad de separar a la astrología de la astronomía. Es decir: establecer criterios científicos sobre los

\footnotetext{
${ }^{1}$ Brion. Marcel. Lorenzo El Magnifico. Barcelona. Joaquín Gil 1942. p. 213.

${ }^{2}$ Sobre el tema ver en especial: Granada, Miguel A. Cosmología, religión y política en el Renacimiento. Ficino, Savonarola, Pomponazzi, Maquiavelo. Barcelona. Anthropos. 1988. parel, Anthony J. The machiavellian cosmos. Londres. Yale University Press. 1992. Vasoli, Cesare. I miti e gli astri. Nápoles. Guida. 1977. Moore, Thomas. Marsilio Ficino's. Astrological Psychology. Londres. Buknell University Press. 1990. En particular ver: Giovanni Pico della Mirandola. Conclusione ermetiche, magiche e orfiche. Milán. Mimesis. 2003. Existen dos versiones en español. A cargo de la misma casa editorial. Conclusiones mágicas y cabalísticas. Barcelona. Obelisco. 1982 y 1996.
} 
sobre naturales que desde siempre han predominado en el campo de la astrología. Debemos decir que tanto Giovanni Pico de la Mirandola como su amigo Gerolamo Savonarola el problema astrológico merecía de toda su atención. Cosa que se percibe en el primero por sus escritos como lo son sus Disputationes adversus astrologiam divinatricem, ${ }^{1}$ Heptaplus y De ente et $u n o^{2}$. En el segundo la cuestión conduce a sospechar que en el oficio del profeta en cuanto mantiene multitud de referentes bíblico-escatológicos y apocalípticos, en estos no cabe ninguna expresión de las artes adivinatorias de origen o extracción pagana ${ }^{3}$.

La relación entre Mirandola y Savonarola se puede plantear en estos términos: así como Nicolás Maquiavelo expulsa de la política a la Fortuna e impone los criterios de la virtú en la acción humana; y así como Rene Descartes asesina al Genio Maligno enseñando que todo eventual error en el campo del conocimiento es estrictamente cosa humana; ellos lo que hacen es intentar expulsar a toda fuerza divina de naturaleza astral pero sobre todo de raíz pagana que se atraviese en nuestros caminos. Lo que se debe valorar es -a nuestro criterio- dos referentes centrales: el primero de ellos a la importancia que tiene la idea de la renovatio humana, es decir, a un cambio al sentido del tiempo y percepción de las cosas humanas. Lo interesante aquí sería indagar en que medida la "posteridad espiritual Joaquín de Fiore" estaba presente en toda esta disputa y hasta que punto en especial su visión apocalíptica conforma parte del escenario en la mentalidad de renovatio que guía y promueve el Renacimiento4.

\footnotetext{
${ }^{1}$ La edición que empleamos corresponde a la editorial Vallecchi. Florencia. 1952. Como dato marginal cabe anotar que esto libro de Pico Della Mirandola está formado por doce libros. Para una introducción a lo que han sido los estudios críticos sobre la filosofía de Pico della Mirandola, ver William G. Graven, op, cit. Véase también de Giovanni Pico della Mirandola. Antologia. Milán. Virgilio. 1973. Introducción de Giuseppe Barone.

2 Editados también por Vallecchi. Florencia. 1942. Esta edición incluye su más famoso y conocido libro: De hominis dignitate. A la fecha existen varias ediciones en español de esta obra de Mirandola. Las que se recomiendan son: De la dignidad del hombre. Madrid. Nacional. 1984. Contiene dos apéndices: Carta a Hermolao Bárbaro y Del ente y el uno; Oración por la dignidad humana. Colombia. Opus Magnus. (Edición bilingüe): De la dignidad del hombre. México. Ramón Llaca. 1996. Con respecto a sus famosas Tesis, las consideramos como parte de un estudio que realizaremos más adelante. Giovanni Pico della Mirandola. Conclusiones nongentae. Le novecento Tesi dell'anno 1486. Florencia. Leo S. Olschki. 1995.

3 Sobre el problema del paganismo durante el Renacimiento ver en especial: Warbur Aby. La rinascita del paganísimo antico. Contributi alla storia della cultura raccolti da Gertrud Bing. Florencia. La Nuova Italia. 1996. Vers. en español. El renacimiento del paganismo. Aportaciones a la historia cultural del Renacimiento europeo. Madrid. Alianza Forma. 2005.

4 Ver Fioere, Gioacchino da. Introduzione all'Apocalisse. Viela. Roma. 1995. Ver también Trattati sui quattro Vangeli. Viele. Roma. 1999. La frase que aquí entrecomillamos es de Henri de Lubac y corresponde a su agudo estudio sobre dicha posteridad. La posteridad espiritual de
} 
La segunda responde a la urgente faena de romper con una mentalidad en la que definitivamente no se termina ni por ser cristiano, ni por ser científico o filósofo ni por ser un individuo virtuoso de acuerdo a los cánones del republicanismo cívico de la república florentina. Es esta última consideración la que continúa atormentando a la modernidad a partir de preguntarse mil veces ¿qué es el Renacimiento?

Para responder a dicha pregunta no es correcto ir a la idea del Conde en la que habla de las cualidades camaleónicas del hombre ${ }^{1}$. Lo cierto es que el Renacimiento es --antes que le cayera encima la pesada losa del Barroco o los horizontes de la racionalidad moderna-- un tiempo en el que la credulidad era la cosa mejor repartida del mundo. Pero como generalmente ocurre, aquí la credulidad se remonta a varias cosas; en especial a ciertos orígenes y a toda una tradición que permite hablar tranquilamente de la cerrada unidad espiritual que predominó en todo el Mediterráneo desde los tiempos antiguos a los del Renacimiento. Las ciudades renacentistas de Italia se convierten de este modo en arena de un conflicto histórico de mayores dimensiones y efectos históricos. Lo que vemos es una disputa en la que los campos simbólicos desempeñan un papel crucial y trascendente. Las ciudades son simplemente carne para los dioses. A los ojos del frate esto es intolerable; y a los del filósofo es motivo de una incomprensible discordia misma que conviene remediar. Lo que sabe el filósofo es que para que su empresa tenga éxito, es necesario tener la idea completa de lo que ha sido el pasado centrado en sus más grandes y representativas personalidades o figuras míticas. Quedarse únicamente con Sócrates, es validar una imagen parcial de ese todo que fue el Mediterráneo. Lo mismo ocurre si sólo en consideración a la pureza del espíritu de la cristiandad adoptamos exclusivamente la imagen de Cristo. Lo que él hace es introducir a Hermes ofreciendo de esta forma la idea total de la conformación de la sabiduría antigua. Lo que se tiene es una triada mítica y mística que funde --en clara concepción cristológica-- con el mítico adánico. Que no es ya el Adán errante y botado a la Tierra. Es el hombre digno de trazo hercúleo que sabe que

Joaquín de Fiore. Madrid. Ediciones Encuentro. 1989. Dos vols. Del mismo autor ver L'alba incompiuta del Rinascimento. Pico Della Mirandola. Op. cit.

1 Ver Carbone Raffaele. "Jean Pic de la Mirandole ou les amphibologies de l'humanisme. La rélation originaire Homme_Nature entre liberté e, culture ét normativité”. En L'Art du Comprendre. Anthropologie philosophieque antropplogie historique herméneutique. París. Pp. 47-66. 
para recuperar la dignidad que le han arrebatado de siempre los dioses, debe romper con ellos. Es ahora cuando Pelagio y Averroes entran por la puerta grande a la casa del filósofo de la que fueron arrojados por san Agustín y por Santo Tomás, respectivamente. Es ahora cuando se erige el Hombre cósmico con toda su grandeza y dignidad. Es el principio del mundo moderno que entiende por fin y tardíamente qué quiere decir exactamente eso de pensar al hombre como amo y señor de la naturaleza. Un profundo referente antropológico que con el tiempo se convierte en las delicias de los filósofos y críticos de la razón instrumental.

El horizonte hipotético sobre los orígenes de esta disputa que es planteada en términos de superar una mentalidad en la que todavía los dioses antiguos tenían mucha vida. De algún modo esto sigue ocurriendo a pasar del tiempo y a pesar de presumir infatigablemente nuestra mentalidad moderna, científica y radicalmente racional. Pero no es el momento de hablar de sus metamorfosis. Lo que si importan es meter un poco de ruido en relación a que a diferencia de nuestro querido y admirado historiador del arte, Irvin Panofski, en vez de considerar si el Renacimiento tiene por origen el cuadro de La adoración de los Reyes de Giotto, conviene mejor trasladarnos a la ciudad de nuestro filósofo y de nuestro predicador e introducirnos al Palacio de Borso d'Este --el Palacio de Schifanoia-- y ver si en esas pinturas, en especial las de contenido astrológico, no radica el secreto profundo sobre el origen del Renacimiento ${ }^{1}$. Lo que motivo y dio pie a esa insuperable producción de imágenes y símbolos entre los cuales no debemos olvidar la importancia de los Triunfos petrarquescos o que la imagen de Hermes ya deambulaba con cierta tranquilidad por la Toscana. Como se sabe y por razones diversas Mirandola como Savonarola fueron grandes viajeros. Uno lo hacía por motivos e inquietudes filosóficas y el otro por motivos religiosos propios a su orden. Lo que el primero descubre en cada estación de estudio que va de Bolonia a París son nuevos horizontes que se traducen, entre otras cosas, en la necesidad de establecer una idea de unidad y concordia filosófica. Para el segundo es la posibilidad de encontrar auditorios para sus famosas predicas. Pero lo que sospechamos es que ellos llevaron la imagen de la mentalidad que reflejan los símbolos de los cuadros del Palacio de

${ }^{1}$ Ver en especial Warburg Aby, cap. 26. op. cit. Vers. en español. (Arte italiano y astrología internacional en el Palazzo Schifanoia de Ferrara) pp. 415-438. 
Schifanoia. Es decir, al verdadero ambiente mental del Renacimiento. Pero ¿qqué era lo que veían en esas imágenes? Seguramente no lo que vemos nosotros desde nuestra mal formada retina moderna. Obras de arte. Excelentes, por cierto. Tampoco veían un mundo absolutamente compatible en el que es posible dar cabida a todo. Es decir, adorar a la Fortuna como a Venus o a la Virgen María. De ahí porque para el llamado Sócrates de Ferrara la fractura del tiempo debería ser radical y esto no tiene nada que ver con el odio que se ha montado sobre él referido a todo lo ocurrido en las famosas Hogueras de la Vanidades. Sin querer discutir a fondo este asunto lo que podemos decir en defensa del frate es que sabía y valoraba mucho al arte; lo que no toleraba --como muchos de nosotros-- es la charlatanería que existe en torno a esta vital e importante actividad humana. Lo que creemos que en su cabeza pesaban más las imágenes del Palacio de Borso d'Este que los frescos de fra Angelico los cuales seguramente veía cada vez que se dirigía a su celda en el Convento de San Marcos. Le preocupaba más cualquier cosa que estaba en el Ciclo dei mesi que los misterios de una Anunciación pintada por el también dominico, fra Angelico.

Lo que relaciona a estas dos personalidades del Renacimiento es la empresa de superar a la astrología y a la magia como lo que son: parte de una profunda tradición cognitiva que respondiendo a su propia sabiduría, no deja de ver en el hombre a un ser infinitamente lacerado por los astros o por infinidad de fuerzas sobre naturales. Incluso las de temperamento providencial. Para ellos si el hombre es objeto de los caprichos de los astros o de las fuerzas de la naturaleza, no existe, entonces, ninguna posibilidad de reconocerse en su libertad. O, peor aún, a su Dios. Y por su cuenta la dichosa Providencia no tendría aquí ningún papel relevante en los destinos humanos. El giro que da Pico della Mirandola a la idea del hombre es tremendo pues se pasa de un teocentrismo a un antropocentrismo. Tremenda es también la tarea de Savonarola pues en su famosa retórica plantea una idea central que tiene que ver con toda su radical crítica a la dominación eclesiástica. Simplemente para él Roma deja de ser el centro del Mundo. De acuerdo a sus predicas, Florencia se erige en la Nueva Jerusalén. Es decir, en la ciudad en la que debe ser abitada por el hombre libre de acuerdo a su republicanismo. Hasta aquí lo que tenemos es una extraña relación de complementariedad en la que la ontología cosmológica 
del filósofo o, si se prefiere, su antropología, se funde con la práctica y con la filosofía política del llamado profeta desarmado. Es verdad que por suerte el Conde no vive los años duros de la República savonaroliana. Como ya se ha mencionado él muere en el fatídico año -si es que es posible fetichizarlo en tales términos-- de 1494. Por tanto no tuvo la oportunidad de ver la escalada de acontecimientos ocurridos en Florencia, ciudad que los dos adoptan como propia, de esa fecha a la muerte del frate. Mirandola no tuvo la oportunidad de vivir la profunda conmoción generada por su leal amigo. Lo que si pudo discutir con el sacerdote son estas como quién sabe que tantas otras cuestiones entre las que debemos considerar por su importancia las bíblicas y en especial las cristológicas en su referencia a la centralidad que adquiere el hombre colocado



\section{Referencias bibliográficas}

ANTONETTI, Pierre (1998). Savonarola “il profeta disarmato". Milán. Biblioteca Universale Rizzoli.

BRION, Marcel (1942). Lorenzo El Magnifico. Barcelona. Joaquín Gil. CAGNA, Nuccia (1949). Gerolamo Savonarola. Turín. Società Editrice Internazionale. CECCUTI, Cosimo. Savonarola. Tra medioevo e Rinascimento. Florencia. Octavo. 1998. FIORE, Gioacchino da (1995). Introduzione all'Apocalisse. Viela. Roma.

(1999) Trattati sui quattro Vangeli. Viele. Roma.

FUMAGALLI Beonio Brocchieri, Mariateresa (1999). Pico della Mirandola. Florencia: PIEMME.

GRANADA, Miguel A. (1988) Cosmología, religión y política en el Renacimiento. Ficino, Savonarola, Pomponazzi, Maquiavelo. Barcelona. Anthropos.

GRAVEN, William (1985). Pico della Mirandola. Un caso Storiografico. Bolonia. Il Mulino.

GUALAZZI, Enzo (1982). Savonarola. Milán. Rusconi.

GUCCIONE, Eugenio (1978). Girolamo Savonarola nel pensiero politico-sociale dei cattolli italiani ttra il XIX e XX secolo. Palermo. Presso L'Accademia.

HUERGA, Álvaro (1978). Savonarola. Reformador y profeta. Madrid. Biblioteca de Autores Cristianos.

LEJENDIO, Luis María de (1960). Savonarola (Estudio biográfico). Madrid. Espasa-Calpe.

LUBAC, Henri de (1977). L'alba incompleta del Rinascimento. Pico della Mirandola. Milán Jaka Book.

(1989) La posteridad espiritual de Joaquín de Fiore. Madrid. Ed. Encuentro. Dos vols. 
MOORE, Thomas (1990). Marsilio Ficino's. Astrological Psychology. Londres. Buknell University Press.

PICO DELLA MIRANDOLA, Gianfrancesco (1999). Vita Hieronymi Savonarolae. Florencia. Leo S. OLschki.

PICO DELLA MIRANDOLA, Giovanni. Conclusione ermetiche, magiche e orfiche. Milán. Mimesis. 2003.

Antologia. Milán. Virgilio. 1973.

Conclusiones nongentae. Le novecento Tesi dell'anno 1486. Florencia. Leo S. Olschki. 1995.

RÍOS MAZCARELLE (2000). Savonarola. Una tragedia del Renacimiento. España. Merino.

ROCCA, Paolo (1964). Giovanni Pico della Mirandola nei sui rapporti di amicizia con Gerolamo Savonarola. Ferrara. Università degli Studi di Ferrara.

SAVONAROLA, Gerolamo (1999). Trattato sul governo di Firenze. Roma. Riuniti.

SCALTRINI, Giacinto (1979). Masciattelli, Piero. Savonarola. Milán. Alpes.

VASOLI, Cesare (1977). I miti e gli astri. Nápoles. Guida.

VILLARI, Pascuale (1930). La storia di Girolamo Savonarola e de sui tempi. Florencia. Felice le Monnier. Dos vols.

WARBUR, Aby (1996). La rinascita del paganísimo antico. Contributi alla storia della cultura raccolti da Gertrud Bing. Florencia. La Nuova Italia.

WEINSTEIN, Donald (1976). Savonarola e Firenze. Profezia e patriotismo nel Rinascimento. Bolonia. Il Mulino.

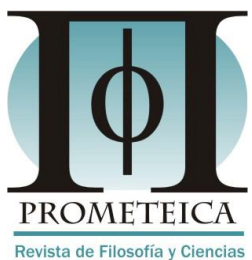

Jorge Velázquez Delgado es Doctor en Filosofía por la UNAM, México, y Profesor e Investigador del Departamento de Filosofía de la Universidad Autónoma Metropolitana-Iztapalapa, México. 